\title{
EL DERECHO DE PROPIEDAD SOBRE LOS DATOS
}

\section{PROPERTY RIGHT ON DATA}

Natalia Jara Fuentealba*

\section{REsumen}

En el mundo actual, los datos son uno de los recursos más valiosos de la economía digital. Sin embargo, no existe una regulación especial para determinar quién es su dueño, ni tampoco existe claridad sobre cómo conviven los distintos derechos sobre este recurso. Por consiguiente, en este artículo, se propone un análisis jurídico que distingue a los datos de su contenido, las bases y el conocimiento extraído a partir de técnicas y disciplinas, para identificar sobre qué bienes intangibles es posible ejercer un derecho real de dominio, conforme a lo dispuesto en la Constitución y las normas de derecho privado chileno. Se demostrará que, pese a que los datos no pueden ser objeto de un derecho de propiedad en los términos del Código Civil, su contenido, bases y estudios, sí pueden ser protegidos por otros tipos de derechos reconocidos en nuestra legislación.

Palabras Clave: Economía de datos; datos; derecho real de dominio; propiedad intelectual; datos personales.

\section{AbSTRACT}

Nowadays, data is one of the most valuable resources in the digital economy. However, there is no special regulation to determine who is their owner, nor is there regulatory clarity on how the different property rights over this type of resource and other related intangible assets coexist. Therefore, in this article, a legal analysis is proposed that distinguishes the data from its content, data bases and the knowledge extracted from tech-

* Abogada de la Universidad de Chile. Asociada del equipo de Energía y TMT en Philippi Prietocarrizosa Ferrero DU \& Uría. Diplomado en Protección de Datos Personales de la Pontificia Universidad Católica de Chile. Dirección postal: El Golf 40, piso 20, Las Condes, Región Metropolitana, Chile. Correo electrónico: natalia.jara@ppulegal.com

Recepción: 2021-05-31; aceptación: 2021-07-19. 
niques and disciplines applied to the data, to identify on which intangible goods it is possible to exercise a property right, in accordance with the Constitution and the rules of Chilean private law. In this sense, this work will demonstrate that, although data cannot be the object of a property right in the terms of the Civil Code, its content, bases and studies, can be protected by other types of rights recognized in our legislation.

KeYwORDs: Data-driven economy; Data; Property Right; Intellectual property; Personal Data.

\section{INTRODUCCIÓN}

En la actualidad, una de las materias primas más preciadas en la economía digital son los datos, porque permiten impulsar el crecimiento económico, la creación de empleos y continuar con el desarrollo de tecnologías disruptivas. Por lo mismo, se ha señalado en diversas publicaciones que los datos son el petróleo del siglo XXI.

Pese a que el desarrollo de una economía basada en datos ha tomado cada vez más fuerza en el ámbito global, la regulación y propiedad de este 102 nuevo recurso aún se encuentra pendiente en la mayoría de las legislaciones. De hecho, el modelo de negocios basado en la denominada ciencia de datos, en el cual se crean resultados novedosos y de gran valor para distintas industrias, ilustra con aún mayor fuerza, la necesidad de identificar quién es el dueño de esta materia prima y los resultados generados en virtud de su procesamiento.

Por esta razón, en el presente artículo, se propone un análisis jurídico que distingue entre los distintos tipos de bienes de la nueva economía digital, los datos, la información contenida en estos, las bases de datos y el conocimiento extraído de sus estudios, para identificar sobre qué bienes es posible ejercer un derecho de propiedad, conforme a la dispuesto en la Constitución y las normas del derecho de privado chileno. En este contexto, una vez expuestas las normas que regulan los distintos tipos de cosas en el Código Civily las normas de propiedad intelectual e industrial aplicables, se podrá concluir que, respecto de los datos como tal, no puede ejercerse un derecho de real de dominio. Sin perjuicio que, respecto de otras creaciones resultantes de su procesamiento -como bases de datos o conclusiones obtenidas de su estudio- y la información o contenido de los datos, en determinadas circunstancias, sí es posible desarrollar mecanismos jurídicos de protección que permiten restringir o limitar su libre circulación para desarrollar un negocio en torno a este valioso recurso. 
Para lograr este objetivo, primero se indicará el contexto histórico y los conceptos más relevantes para efectos de esta investigación. A saber, los datos, bases de datos y las nuevas tecnologías y disciplinas destinadas a realizar un análisis de los datos, como Big Data y ciencias de datos. Se expondrá cómo estos diferentes activos o bienes intangibles se encuentran regulados en nuestro ordenamiento jurídico y se procederá a identificar los distintos mecanismos jurídicos de protección, entre ellos el derecho de propiedad y otros derechos relacionados de propiedad intelectual. Por último, se desarrollarán algunas reflexiones sobre esta materia para la nueva discusión constitucional, principalmente en torno al impacto de discutir el alcance de los objetos amparados por el derecho de propiedad, en el contexto de la nueva economía digital, basada en bienes incorporales inclasificables según las normas del Código Civil, como los datos.

\section{UNA TRANSFORMACIÓN IMPULSADA POR DATOS}

Una sociedad digital hiperconectada y con acceso a cada vez más tecnologías que permiten generar y almacenar grandes volúmenes de datos, en tiempo real, rápidamente ha forzado a vivir en una realidad en la cual existen infinitas oportunidades para aplicar un conocimiento derivado de los datos. En efecto, en la literatura ya se habla de un "diluvio de datos", porque todos los procesos de la vida cotidiana o industrial terminan produciendo información que puede ser guardada, sin importar su magnitud, y procesada a gran velocidad por distintas tecnologías.

En este contexto, el crecimiento de la economía de datos es inconmensurable, porque todas las personas no solo generan datos, sino, también, son "un dato en sí mismo", que junto con los obtenidos por los diversos dispositivos interconectados a la red -sensores, computadores, smartphones, tablets, smartwatches, entre otros-, cada vez acumulan más y más información, disponible para ser procesada por cualquiera que tenga interés en extraer conocimiento de su recopilación. Por lo mismo, ha surgido el concepto "economía de datos", que consiste en:

"El conjunto de iniciativas, actividades y/o proyectos cuyo modelo de negocio se basa en la exploración y explotación de las estructuras de bases de datos existentes (tradicionales y procedentes de nuevas fuentes) para identificar oportunidades de generación de productos y servicios"1.

\footnotetext{
${ }^{1}$ LóPEz (2017), p. 23.
} 
En la sociedad actual, los datos se han transformado en el nuevo centro de la nueva economía, ya que son un recurso esencial para el crecimiento económico, la creación de empleos y el desarrollo de nuevas tecnologías disruptivas. No obstante, es relevante tener presente que estos, por sí mismos, no tienen valor alguno, porque requieren de un "tratamiento, procesamiento y análisis científico de donde se extrae conocimiento útil y original" 2 . Por esta razón, se hace una analogía entre los datos y el petróleo, porque ambos requieren de un proceso de refinamiento -tratamientopara ser útiles en cualquier actividad o industria. A su vez, también se ha concluido que la relevancia de los datos no reside en estos considerados en forma aislada, sino en el conjunto de estos, porque existe una proporción directa en la cantidad de datos y la probabilidad de conseguir resultados útiles a través de un adecuado procesamiento ${ }^{3}$. Por ende, a mayor volumen de datos, más probabilidad de conseguir un resultado auspicioso y valioso a partir de su tratamiento.

Con todo, antes de desarrollar las técnicas y disciplinas dirigidas a realizar procesamiento y extraer conocimiento valioso a partir de los datos, se expondrá el concepto y las clasificaciones más importantes de este recurso, así como las creaciones originadas sobre la base de su agrupación, esto es, las bases de datos. Pues, antes de analizar cómo serán tratados

104 estos objetos bajo la legislación chilena, es necesario identificar los distintos tipos de bienes involucrados en la nueva economía digital.

\section{Datos: \\ Una materia prima valiosa en el siglo XXI}

El concepto 'dato' es probablemente una de las expresiones más utilizadas en la era digital, porque hace alusión a la información procesable por un computador. Sin embargo, pese a que existe dicha acepción del concepto ${ }^{4}$, para efectos del presente artículo, se tendrá como punto inicial el significado más amplio, que define al dato como toda "información sobre algo concreto que permite su conocimiento exacto o sirve para deducir las consecuencias derivadas de un hecho ${ }^{5}$ ". De esta manera, como se desarrollará en las secciones siguientes, la economía de datos hace más conveniente distinguir la fuente del conocimiento -el dato "bruto"- del conocimiento generado gracias a la recolección de un recurso o materia prima denominada "dato".

\footnotetext{
${ }^{2}$ López (2017), p. 23.

${ }^{3}$ García (2020), p. 28.

${ }^{4}$ Real Academia Española (2014).

${ }^{5}$ Ibid.
} 
Por su parte, las regulaciones técnicas, como las Normas ISO sobre Tecnologías de la Información, también definen el dato en forma similar, ya que indican que este consiste en toda "representación reinterpretable de información de manera formalizada adecuada para la comunicación, la interpretación o el procesamiento" ". En consecuencia, el dato como tal, es una cosa distinta al conocimiento que se obtiene a partir de él.

Asimismo, se ha señalado que los datos son información representada simbólicamente y, como tal, tienen dos aristas o dimensiones. Una realidad física vinculada con el soporte del dato y, una realidad inmaterial, consistente en el contenido mismo de la información, la cual puede ser susceptible de duplicarse en forma ilimitada ${ }^{7}$. De hecho, se habla del "cuerpo y alma del dato", pese a que el dato no se confunde con ninguno de estos elementos, porque cada vez que se "manifiesta", el soporte y el contenido están siempre presentes ${ }^{8}$.

Ahora bien, como se explicaba en el apartado anterior, el "petróleo del siglo XXI" puede provenir de cualquier fuente, desde una persona hasta una máquina interconectada con la $\operatorname{red}^{9} \mathrm{y}$, a su vez, puede expresarse o encontrarse en distintas formas, desde un documento, imagen, texto, videos, mensajes, pedidos, visitas a un sitio web, búsquedas en línea hasta la cantidad de ventas, horarios en que se realiza una transacción, boletas, etc. Por lo mismo, para obtener un resultado valioso a partir de su estudio, será necesario analizar los datos, con apoyo de diversas técnicas y tecnologías, junto con otras -varias-agrupaciones de datos que permitan a los expertos generar correlaciones, identificar patrones, etcétera.

No obstante, antes de abordar cómo se pueden disponer los datos para ser procesados por técnicas y tecnologías, es necesario conocer algunas de sus más importantes clasificaciones. Pues, como se verá a lo largo del artículo, en muchas ocasiones, el tipo de dato tiene un impacto para efectos de determinar la regulación jurídica aplicable en el tratamiento. En consecuencia, se expondrán los siguientes criterios de clasificación:

a) El soporte sobre el cual se materializa el dato;

b) Datos brutos y derivados;

${ }^{6}$ Norma ISO/IEC 2382-1, véase LóPEz (2017), p. 23.

${ }^{7}$ Torre de Silva y López de Letona (2019), p. 830.

${ }^{8}$ Ibid.

${ }^{9}$ La comunicación entre máquinas se conoce en la industria como "M2M", gracias a la expresión en inglés machine to machine. En la actualidad, una de las tendencias tecnológicas con más impacto en esta materia es la "Internet de las cosas" (Internet of Things o IoT), la cual consiste en la "tecnología basada en la conexión de objetos cotidianos a internet que intercambian, agregan y proceso información sobre su entorno físico para proporcionar servicios de valor añadido a los usuarios finales”. MoIsés (2020), p. 73. 
c) Datos personales, anonimizados y datos no personales;

d) Datos públicos y privados.

a) Clasificación de los datos según el soporte en el que se materializan

Esta clasificación consiste en categorizar a los datos según si estos pueden o no ser procesables a través de una máquina. Por una parte, se encuentran los datos analógicos, que consisten en toda fuente de información materializada en un soporte físico, sin posibilidad de que estos sean interpretados por una máquina. Por ejemplo, documentos históricos plasmados en papel -sin soporte digital-, fotografías, documentos, cartas, etc. Y, por otro lado, están los datos digitales que consisten en todos aquellos expresados en valores números discretos -binarios o bits- que una máquina puede procesar $^{10}$, como una imagen o documento escaneado, los datos que se generan por navegar en internet, información escrita en cualquier programa de computador, entre otros.

Desde el punto de vista jurídico, esta clasificación es relevante porque a diferencia de los datos analógicos, los datos digitales generalmente se encuentran disponibles en la red, abiertos a todo público y, por ende, pueden levantarse cuestionamientos respecto a su acceso, control y has106 ta su propiedad. Asimismo, cabe destacar que, la dimensión "física" del dato es lo que determina la conexión de los datos con un lugar o jurisdicción ${ }^{11}$ e, incluso, como se verá en la siguiente sección, puede significar la corporalidad necesaria para ejercer un derecho real de dominio en los términos del Código Civil. Por lo mismo, es innegable que el soporte del dato puede generar importantes consecuencias, como la ubicación de un servidor que sirve para fijar un punto de conexión desde la mirada del derecho internacional privado; fijar la competencia de un tribunal; lugar del delito, etc. Sin embargo, es relevante distinguir entre la dimensión física y el contenido o información que consta en el dato, para entender el alcance de los derechos disponibles en nuestro ordenamiento jurídico.

Con todo, dado que el objetivo del presente artículo se limita a estudiar las implicancias de la economía de datos en el derecho privado, solo se analizará la relevancia del soporte del dato para determinar eventuales derechos de propiedad sobre estos, las bases de datos y los conocimientos extraídos una vez finalizadas las actividades de procesamiento.

\footnotetext{
${ }^{10}$ García (2020), p. 24.

${ }^{11}$ Torre de Silva y López de Letona (2019), p. 830.
} 
b) Clasificación según

su fuente conocimiento

En una sociedad altamente interconectada, gradualmente comienzan a surgir "datos sobre datos". Es decir, datos elaborados sobre la base de datos "brutos" o "primarios", que son representaciones simbólicas de información obtenida de la "realidad".

En este contexto, es necesario tener presente que existen datos "brutos" o "primarios", cuando estos representan simbólicamente la realidad en virtud de una fuente directa. Por ejemplo, un artículo, escritos, videos, fotografías, etc. Y existen datos "derivados" o "secundarios", que se construyen sobre la base del análisis de los datos "brutos". En general, esta distinción es relevante en materia de propiedad intelectual, ya que, si bien en ambos tipos de datos se puede apreciar una creación intelectual de una persona natural, las nuevas tecnologías y técnicas de procesamiento pueden transformarse en un problema en el momento de calificar a los datos derivados como una obra protegida por propiedad intelectual. Por ende, pueden existir inconvenientes en torno a su titularidad.

No obstante, la titularidad sobre los distintos tipos de activos generados en la economía basada en datos se analizará en la segunda sección, en este punto, solo es relevante señalar que, frente a la clasificación de datos primarios y derivados, pueden existir problemas relacionados con la licitud de la fuente. Esto dado que los datos "brutos" pueden estar regulados con un marco normativo especial, por ejemplo, los datos personales; pueden existir problemas relacionados con quien produce la obra -si una máquina o un algoritmo puede ser el "autor" de una creación intelectualy, también para la aplicación de los conceptos de obras "originarias" y "derivadas" en la Ley n. ${ }^{\circ} 17336$. Este último punto, será expuesto con mayor profundidad en el apartado sobre la clasificación de las bases de datos según el origen de los datos.

c) Clasificación según el contenido:

Datos personales, datos no personales y datos anonimizados

En la actualidad, una de las clasificaciones con mayor relevancia jurídica es aquella que distingue entre los datos que identifican o permiten identificar a una persona natural. Estos son los denominados "datos personales", a los cuales se les reconoce un valor inherente mayor o distinto de aquellos "impersonales". Por lo mismo, los primeros gozan de una regulación especial en casi todas las jurisdicciones del mundo.

En el derecho chileno, los datos personales se definen, al igual que en la gran mayoría de los países, como aquellos datos "relativos a cualquier información concerniente a personas naturales, identificadas o identifica- 
bles" ${ }^{\prime 2}$. Es decir, consiste en toda información que permita reconocer la identidad de una persona, como su imagen, su número de identificación nacional, el número de un pasaporte, nombre, domicilio, nacionalidad, sexo, hábitos de compra, dirección IP, etcétera.

A su vez, dentro de esta categoría existen subclasificaciones como, por ejemplo, los datos sensibles que, según la legislación chilena, son:

"Aquellos datos personales que se refieren a las características físicas o morales de las personas o a hechos o circunstancias de su vida privada o intimidad, tales como los hábitos personales, el origen racial, las ideologías y opiniones políticas, las creencias o convicciones religiosas, los estados de salud físicos o psíquicos y la vida sexual" ${ }^{\prime 3}$.

Sin perjuicio de lo anterior, cabe tener presente que en otras legislaciones existen más subcategorías de datos sensibles, como los datos biométricos ${ }^{14}$ o los datos genéticos ${ }^{15}$, los cuales están siendo considerados en el proyecto de ley que regula la protección y el tratamiento de los datos personales y crea la Agencia de Protección de Datos Personales ${ }^{16}$, que hoy se está tramitando en el Congreso.

108 Asimismo, se puede señalar una categoría intermedia entre los datos personales y no personales, en la cual se identifican los "datos seudonimizados". Esto es, el:

"Tratamiento de datos personales de manera tal que ya no puedan atribuirse a un interesado sin utilizar información adicional, siempre que dicha información adicional figure por separado y esté sujeta a medidas técnicas y organizativas destinadas a garan-

${ }^{12}$ Art. 2, letra f) de la Ley n. ${ }^{\circ} 19628$ de 1999.

${ }^{13}$ Art. 2, letra g) de la Ley n. ${ }^{\circ} 19628$ de 1999.

${ }^{14}$ En el GDPR, se definen los datos biométricos como los "datos personales obtenidos a partir de un tratamiento técnico específico, relativos a las características físicas, fisiológicas o conductuales de una persona física que permitan o confirmen la identificación única de dicha persona, como imágenes faciales o datos dactiloscópicos”.

${ }^{15}$ En el GDPR se definen como aquellos "datos personales relativos a las características genéticas heredadas o adquiridas de una persona física que proporcionen una información única sobre la fisiología o la salud de esa persona, obtenidos en particular del análisis de una muestra biológica de tal persona".

${ }^{16}$ Boletín n. ${ }^{\circ} 11144-07$. Proyecto de ley que regula la protección y el tratamiento de los datos personales y crea la Agencia de Protección de Datos Personales de fecha 15 de marzo de 2017, ingresado en la Cámara del Senado. Para mayor información consultar www.camara.cl/legislacion/ProyectosDeLey/tramitacion.aspx?prmID=11661\&prmBoletin 
tizar que los datos personales no se atribuyan a una persona física identificada o identificable" ${ }^{17}$.

Sin embargo, en la legislación vigente esta categoría no se encuentra definida y, en caso de permitir la identificación de una persona natural, debiesen interpretarse, para todos los efectos legales, como un dato personal ${ }^{18}$.

Por otro lado, constituyen datos "impersonales" toda información que no identifica o permite identificar a una persona natural. Por ejemplo, los datos de personas jurídicas, datos recopilados de un proceso industrial, datos del ambiente, datos macroeconómicos, resultados financieros, etc. En general, el tratamiento de la información no personal no está sujeto a una regulación específica y, en la práctica, dependiendo de si existe algún esfuerzo en su recolección, organización o procesamiento, se consideran como propiedad intelectual de la persona o entidad que los genera y obtiene resultados sobre estos.

En este caso, considerando que la clave de la categoría definida es que los datos no identifiquen o permitan identificar a una persona natural, también se pueden encasillar datos que en el pasado fueron personales, pero que, en virtud de un procesamiento especial, han dejado de serlo porque es imposible rastrear a una persona natural con la información resultante. Por ejemplo, los datos anonimizados o estadísticos -que corresponden a datos "derivados", según el criterio de clasificación anterior- los cuales, hoy, se definen en la ley como aquellos que "en su origen, o como consecuencia de su tratamiento, no pueden ser asociados a un titular identificado o identificable" ${ }^{19}$.

Como se mencionaba anteriormente, esta es una de las clasificaciones de datos con mayor impacto jurídico, porque la protección de datos personales en el derecho chileno está consagrada en el ámbito constitucional ${ }^{20}$, y su tratamiento siempre deberá hacerse en la "forma y condiciones que determine la ley". Asimismo, en virtud de que la protección de datos personales es un derecho fundamental, también pareciera ser que es irrelevante el tipo de relación que tiene el titular con sus propios datos personales, porque para la normativa vigente $-\mathrm{y}$ en esto se incluye el proyecto de ley sobre protección de datos personales- el énfasis no está en determinar si los datos personales son patrimoniales o no, sino únicamente en resguardar el derecho del titular de proteger sus datos personales.

\footnotetext{
${ }^{17}$ Art. 4, n. ${ }^{\circ} 5$ del GDPR.

${ }^{18}$ Torre de Silva y López de Letona (2019), p. 833.

${ }^{19}$ Art. 2, letra e) de la Ley n. ${ }^{\circ} 19628$ de 1999.

${ }^{20}$ Art. 19 , n. ${ }^{\circ} 4$ de la Constitución Política de la República.
} 
Por lo mismo, en un nuevo contexto como el de una economía basada en datos, pareciera interesante al menos preguntarse si quien genera la materia prima -el titular- puede enriquecerse u obtener algún provecho de los resultados obtenidos por el procesamiento de sus datos. Con todo, esto se analizará en la sección siguiente, referida a exponer sobre los aspectos normativos relevantes para desarrollar este modelo de negocios en el medio nacional. Por su parte, en el caso del tratamiento de los datos "impersonales", al menos en Chile no existe una regulación particular. Por ende, a priori pareciera existir una luz verde para realizar su tratamiento sin limitación alguna, aunque como se podrá demostrar, dicha conclusión no es tan simple de determinar, si existe un derecho de propiedad intelectual sobre los datos.

d) Clasificación según si los datos son públicos o privados

En el derecho chileno, tanto las cosas como las personas pueden ser clasificadas según si pertenecen al ámbito público o privado. Sin perjuicio de que en el siguiente capítulo se demostrará que los datos tienen una naturaleza jurídica difícil de clasificar bajo las normas del derecho civil, por el momento es interesante reflexionar sobre si, en el supuesto que se 110 admitiera un derecho de propiedad sobre estos bienes intangibles, existen datos que le pertenecen a los particulares o, bien, le pertenecen a la nación toda ${ }^{21}$.

En el primer caso, se estará frente a datos privados, cuyo derecho de propiedad deberá ser respetado por cualquier persona, en virtud de las características del derecho real de dominio ${ }^{22}$ y, en el segundo caso, se estará en presencia de datos públicos, cuyo dominio le pertenece a la nación y su uso a todos los habitantes ${ }^{23}$.

La relevancia de esta clasificación es que plantea a un problema -quizá aparente- en la nueva economía de datos, porque los datos públicos presentarían las siguientes características:

i) Su uso les pertenece a todos los habitantes de la nación y

ii) Son incomerciables, porque por su finalidad o destino están fuera del comercio.

Por lo mismo, sería difícil excluir a los terceros que puedan estar interesados en usar información de libre acceso al público, cuando no existe otro derecho comprometido, como la protección de un dato personal o de propiedad intelectual.

${ }^{21}$ Peñailillo (2006), p. 63.

${ }^{22}$ Op. cit., p. 65.

${ }^{23}$ Art. 589 del Código Civil. 
En el extranjero, la discusión sobre la propiedad pública o privada de los datos principalmente se vincula con el principio del libre acceso a la información disponible en internet ${ }^{24}$. Pues, si bien en ciertos casos se entiende que priman ciertos derechos sobre dicho principio -por ejemplo, los datos personales o aquellos contenidos protegidos por derechos de autor-, es necesario cuestionarse si otro tipo de datos -como datos no personales, estadísticos, etc.- permiten excluir a terceros respecto de su uso o disposición. En Chile, el hecho de que sea público o privado podría sentar las bases para discutir sobre la legitimidad de la riqueza generada por analizar datos públicos, ya que como se indicó previamente, la doctrina civil ha entendido que los bienes públicos están fuera del comercio.

Sin perjuicio de lo anterior, para efectos de este artículo bastará plantear si es posible ser dueño de los datos como bienes jurídicos individualmente considerados. No obstante, para esta discusión también será relevante distinguir entre los diversos bienes en juego en estos modelos de negocios. Ellos son: los datos, su contenido, las bases de datos y el conocimiento extraído del procesamiento de la información, ya que el objetivo principal es analizar cómo pueden desarrollarse las nuevas relaciones jurídicas en la reciente economía basada en datos.

Atendido lo anterior, previo a desarrollar las implicancias jurídicas en reconocer los distintos tipos de activos en la economía de datos, a continuación, se expondrá el concepto bases datos y las nuevas técnicas y tecnologías desarrolladas para extraer conocimiento valioso de estos recursos. En consecuencia, será posible dimensionar cómo el derecho civil, junto con el derecho constitucional de protección de datos personales y el derecho de propiedad, pueden aportar para regular las relaciones desarrolladas en el nuevo modelo de negocios, basado en explotar uno de los recursos más valiosos en la era digital.

\section{Bases datos: El conjunto es distinto a la parte}

Un conjunto puede nacer por la agrupación de cosas o individuos que comparten una característica común o, bien, porque la suma de todas de sus partes crea algo completamente nuevo y distinto de cada parte considerada de forma individual.

En cualquier caso, es posible encontrar ejemplos de ambos tipos de conjuntos en el derecho civil chileno. Por una parte, existen casos donde el todo solo está conformado por la suma de distintos elementos individuales, como el grupo de derechos reales inscritos sobre la misma propiedad raíz

${ }^{24}$ Torre de Silva y López de Letona (2019), p. 842. 
$\mathrm{y}$, por otro lado, conjuntos que superan cada parte que lo conforma, como el patrimonio que consiste en un atributo distinto a la mera agrupación de activos y pasivos que lo componen. De este modo, existen casos donde la agrupación de cosas que comparten características comunes crea una entidad nueva y compleja, distinta a la suma de sus partes y que no se recompone con la mera suma de sus componentes.

En este contexto, es fácil imaginar por qué una base de datos es un concepto difícil de definir, ya que tradicionalmente se ha entendido como una mera agrupación de datos. No obstante, en distintas disciplinas también se ha resuelto que las bases de datos consisten en una agrupación más compleja que una mera sumatoria de datos, porque dicha agrupación de información persigue un fin principal ${ }^{25}$.

En general, dicho propósito consiste en "el acceso a la información de una forma más rápida que si ésta no se hubiera incluido en la base de datos" ${ }^{\prime 26}$, porque el verdadero valor de una base reside en que se transforme en un método eficiente para acceder a la información. Por lo mismo, se dice que una base de datos cumple su función cuando es completa y comprensible. Esto es, que contenga toda la información relevante, excluyendo todo aquello que no importe para los objetivos propuestos por compilador y, a su vez, que permita a los usuarios conocer la información por medio de un sistema de organización particular definido por dichos propósitos de compilación ${ }^{27}$. En consecuencia, tanto la estructura como el contenido de una base de datos, se definen sobre el fundamento de un fin que busca su creador, el cual puede simplemente consistir en facilitar el acceso a la información contenida en los datos recopilados.

Por consiguiente, se puede concluir:

"Cualquier conjunto de datos no es por sí mismo una base de datos, sino sólo aquellos que, en primer lugar, estén ordenados de una forma concreta y, en segundo lugar, que permitan su consulta o acceso a estos más ágilmente que si no estuvieran organizados, es decir, que ofrezcan información" 28 .

Por lo mismo, para construir una base de datos se requiere que se cumplan dos requisitos:

i) Recopilación de información, la cual puede provenir de datos protegidos o no por la legislación vigente, por ejemplo, datos personales, información privada y confidencial, datos impersonales, etc. y

\footnotetext{
${ }^{25}$ García (2014), p. 29.

${ }^{26}$ Ibid.

${ }^{27}$ Op. cit., p. 30.

${ }^{28}$ Ibid.
} 
ii) Organización metódica de la información, gracias a la cual no solo se selecciona la información relevante para responder a un fin determinado, sino, también, se organiza de una forma en que la información sea legible.

Pues, el objetivo final es responder a una necesidad de acceso a la información, que permita la búsqueda de un dato o información, en forma táctica y estratégica.

Atendido lo anterior, surgen distintas clasificaciones de bases de datos, las cuales son relevantes para determinar el grado de protección de jurídica que pueden recibir, sea cual sea su contenido. A modo de ejemplo, la clasificación puede establecerse según su:

a) Estructura y

b) Origen.

El fundamento de estos criterios de clasificación se desarrolla a continuación:

a) Clasificación según la estructura

de la base de datos

Una primera clasificación de las bases de datos consiste en distinguir si la estructura de la base está conformada por criterios originales de recolección, selección y organización o disposición de contenido. Dicho de otro modo, es una creación que goza de originalidad, porque es resultado de un trabajo creativo del compilador y no consiste en una mera copia de una estructura anterior con datos distintos.

Para el derecho chileno, al igual que en otras legislaciones, esta clasificación es trascendental, porque determina la aptitud de una base de datos para ser protegida por derechos de autor. En efecto, la Ley n. ${ }^{\circ} 17336$ establece que se protegen con derechos de autor:

"Los derechos que, por el solo hecho de la creación de la obra, adquieren los autores de obras de la inteligencia en los dominios literarios, artísticos y científicos, cualquiera que sea su forma de expresión, y los derechos conexos que ella determina” ${ }^{29}$.

Por lo mismo, se desprende que las exigencias que toda obra debe cumplir para ser protegida por derechos de autos son:

i) Expresión, en el sentido de que se trate de una obra representada o exteriorizada en una forma determinada y que permite identificar su contenido;

ii) Originalidad, porque al hablar de "creación", se entiende que la

${ }^{29}$ Art. 1 de la Ley n. ${ }^{\circ} 17336$ de 1970. 
"obra tiene una individualidad, consistente en el sello personal que le otorga el autor a través de una particularidad de su forma de expresión" 30

y, por último, que consista en una

iii Obra de la inteligencia, en los dominios literarios, artísticos y científicos, ya que la propiedad intelectual no protege cualquier resultado del intelecto.

En este contexto, la misma ley establece que están especialmente protegidos por los derechos de autor distintas categorías de obras literarias, artísticas y científicas, entre las cuales se destacan, para efectos del presente artículo, las bases de datos. En efecto, el art. 3, n. ${ }^{\circ} 17$ de la Ley n. ${ }^{\circ} 17336$ señala:

"Las compilaciones de datos o de otros materiales, en forma legible por máquina o en otra forma, que por razones de la selección o disposición de sus contenidos, constituyan creaciones de carácter intelectual" 31 .

Por consiguiente, solo las bases de datos originales son protegidas por derechos de autor -importante destacar que el dueño será el autor, una persona natural por el "sólo hecho de su creación"- cuando:

"El criterio que se utiliza para seleccionar y determinar la disposición del contenido de la obra permite que ese trabajo sea considerado una creación intelectual propia del autor, ya que, esos elementos la dotan de originalidad" 32 .

En cambio, las bases de datos no originales no gozan ningún tipo de protección particular.

Ahora bien, la protección de las bases de datos no alcanza a los datos que la componen y es distinta a los derechos que subsistan respecto de los datos o materiales contenidos en la compilación ${ }^{33}$, como señala el art. 3, n. ${ }^{\circ} 17$ de la Ley n. ${ }^{\circ} 17336$ :

"Esta protección no abarca los datos o materiales en sí mismos, y se entiende sin perjuicio de cualquier derecho de autor que subsista respecto de los datos o materiales contenidos en la compilación”34.

\footnotetext{
${ }^{30}$ Walker (2020), p. 73.

${ }^{31}$ Art. 3, n. ${ }^{\circ} 17$ de la Ley n. ${ }^{\circ} 17336$ de 1970.

${ }^{32}$ Walker (2020), p. 91.

${ }^{33}$ Op. cit., p. 90.

${ }^{34}$ Art. 5, letra h) de la Ley n. ${ }^{\circ} 17336$ de 1970.
} 
Es decir, no son parte del derecho de autor que protege la base de datos, los datos mismos -las partes- que componen este conjunto. De hecho, los datos o materiales contenidos en la compilación pueden tener una protección individual a través del derecho de propiedad -si se acoge la doctrina de que existe un derecho de dominio sobre los datos-, derechos de autor o tutela especial otorgada en caso de que los datos compilados en la base sean datos personales.

b) Clasificación según el origen de los datos que la componen

Una segunda clasificación de las bases de datos está enfocada en el origen del contenido. En otras palabras, consiste en aplicar los conceptos de obra originaria y derivada presente en la Ley n. ${ }^{\circ} 17336$. Según la normativa vigente en materia de propiedad intelectual, la obra originaria es "aquella que es primogénitamente creada" ${ }^{35} \mathrm{y}$, la obra derivada es:

"Aquella que resulte de la adaptación, traducción u otra transformación de una obra originaria, siempre que constituya una creación autónoma".

Por consiguiente, una base de datos originaria extrae sus datos de hechos materiales o primarios ${ }^{36}$, y una base de datos derivada se construye a partir de datos primarios, esto es, combinando una o más bases de datos preexistentes $^{37}$. Sin perjuicio que también es posible construir bases de datos derivadas a partir de bases de datos originarias, independiente de las características de los datos recopilados, conforme a lo dispuesto en las normas que regulan los derechos de autor.

La importancia de esta clasificación es que la creación de una obra derivada necesariamente exige la autorización del autor o de la obra originaria, si dichos derechos están vigentes, porque la invención de este tipo de obras implica un acto de transformación o variación de la obra originaria, que resulta en una nueva creación ${ }^{38}$. De hecho, la obra originaria, en este caso, puede consistir en los datos o en una base de datos originaria.

En consecuencia, la creación de una base de datos derivada siempre requiere respetar los derechos de autor, si es que existen, de las bases de datos originaria. Asimismo, al igual que en la clasificación anterior, esto también debe entenderse en forma separada, pero complementaria, de

\footnotetext{
${ }^{35}$ Art. 5, letra i) de la Ley n. ${ }^{\circ} 17336$ de 1970.

${ }^{36}$ García (2014), p. 33.

${ }^{37}$ Ibid.

${ }^{38}$ WALKer (2020), p. 94.
} 
los derechos sobre los datos "brutos" o "primarios" tratados en la creación una base de datos derivada. Pues, este nuevo trabajo es distinto a las partes que lo componen y, sobre estos datos, pueden existir derechos de autor o, incluso, protección especial por tratarse de datos personales.

En este punto, es relevante señalar que en Europa ya se ha detectado un problema jurídico respecto una subcategoría de bases de datos derivadas, denominadas bases datos spin offo sole source. Estos consisten en bases de datos creadas por la recopilación de materiales ya existentes o, bien, sobre la base de una única fuente de información. Por ende, otorgar "derechos exclusivos a sus titulares podría impedir la creación de productos derivados y la circulación de servicios ${ }^{39}$ ", lo cual puede ser un problema en el marco de la nueva economía digital basada en datos.

No obstante, es perfectamente posible que estas bases de datos spin off constituyan una creación intelectual nueva y original, susceptible de ser protegida por derechos de autor. Por esta razón, es interesante cuestionarse si eventualmente será necesario tomar decisiones de orden político-económico, respecto de la protección que merecen nuevos desarrollos como bases de datos en la era del Big Data y la ciencia de datos.

\section{Revolución del tratamiento de datos masivos: Big Data y ciencia de datos}

En la nueva economía basada en datos, existen diversas tecnologías que permiten recolectar, almacenar y procesar datos de forma automática, a partir de cualquier fuente disponible en la red. Sin embargo, para efectos del presente artículo, la más importante es la tecnología conocida como Big Data, porque ilustra de mejor manera la magnitud de las cantidades de datos transadas en los nuevos modelos de negocios y las potencialidades que se pueden obtener del estudios de estos, mediante el empleo de mejores herramientas y capacidades tecnológicas.

El Big Data se puede conceptualizar como la:

"Utilización de herramientas tecnológicas para recolectar datos masivos y darle un tratamiento que nos permita buscar, con ayuda de la minería de datos, patrones que servirán para analizarlos e interpretarlos" ${ }^{40}$

o, bien, como:

"Una nueva generación de tecnologías y arquitecturas diseñadas para extraer valor económico de grandes volúmenes de datos he-

${ }^{39}$ García (2014), p. 34.

${ }^{40}$ Sánchez (2021), p. 27. 
terogéneos habilitando una captura, identificación y/o análisis a alta velocidad" ${ }^{41}$.

Es decir, consiste en un conjunto de técnicas y herramientas tecnológicas, que permiten realizar el procesamiento de grandes volúmenes de datos variados, a gran velocidad. Por lo mismo, su valor reside en que permite extraer conocimiento a través de procesos de "refinamiento" del nuevo petróleo crudo, esto es, los datos antes de ser procesados.

Por su parte, también han surgido nuevas disciplinas y herramientas, entre las cuales cabe destacar la "ciencia de datos", que consiste:

"En las técnicas que, además de realizar un análisis descriptivo, posibilitan anticipar o predecir sucesos futuros (análisis predictivo) e incluso prescriptivos" ${ }^{\prime 2}$.

En este sentido, la ciencia de datos utiliza modelos matemáticos para deducir patrones y tendencias existentes en los datos analizados, en situaciones donde probablemente dicho descubrimiento habría sido complejo, en virtud de la cantidad de los datos disponibles o la relaciones que existan entre estas representaciones de información ${ }^{43}$.

Hoy, el Big Data y disciplinas como la ciencia de datos, generan conocimiento valioso a partir del estudio de los datos, que permite a las empresas tomar decisiones relacionadas con mejorar la eficiencia de su productividad, ahorrar costos, analizar a sus clientes, ofrecer servicios en forma personalizada, prevención de fraude, etc. Empero, cada vez se observan más dificultades normativas para justificar la existencia de un derecho de propiedad sobre los resultados obtenidos en esta ciencia, porque la regulación relacionada con estas materias, específicamente las normas de propiedad intelectual e industrial, no están pensadas para proteger estas conclusiones, si estas no son generadas en forma directa por el intelecto humano, sino de un algoritmo o de nuevas tecnologías como la I.A.

Por lo tanto, existe un eminente riesgo para el desarrollo del negocio sobre la base de los datos, porque los desarrolladores y expertos, en ciertas ocasiones, no podrán ejercer un derecho de propiedad sobre sus conclusiones o resultados, ni siquiera bajo la figura de propiedad intelectual. No obstante, existen algunas alternativas de protección, sobre todo desde el punto de los secretos empresariales y los mecanismos contractuales que

\footnotetext{
${ }^{41}$ PuYol (2014), p. 486.

${ }^{42}$ Op cit., p. 25.

${ }^{43}$ Op. cit., pp. 480-481.
} 
permiten restringir la circulación de cierto contenido o información, las cuales serán desarrolladas a continuación.

\section{EL DERECHO DE PROPIEDAD SOBRE LOS DATOS \\ Y LOS NUEVOS ACTIVOS GENERADOS EN LA ECONOMÍA DIGITAL}

En la economía de datos, es posible identificar distintos activos generados basados en el trabajo realizado sobre las representaciones simbólicas de información, esto es, desde el dato mismo, hasta el resultado del procesamiento de este recurso o el dato individualmente considerado, hasta la base de datos generada con una finalidad específica. De este modo, quizá una de las preguntas más relevantes en este nuevo modelo de negocios es: ¿Quién es el dueño del dato, una de las materias primas más valiosas de la economía digital?, ces realmente un dato un bien sujeto a protección jurídica?

Para responder esta pregunta se analizará el concepto de dato desde la perspectiva del derecho civil, porque en la legislación chilena no existe una norma especial que regule la relación de jurídica entre una persona y los datos, salvo cuando dichos datos son de carácter personal. Por lo mismo, 118 uno de los objetivos de la presente investigación es determinar cuál es la naturaleza jurídica de los datos en el derecho nacional y estudiar si sobre estos bienes es posible ejercer un derecho de dominio. Ello, porque en un contexto de economía digital, los mecanismos de protección que se puedan ejercer sobre uno de los recursos más valiosos del siglo XXI es relevante para mitigar riesgos y propender al desarrollo de nuevos negocios.

Por esta razón, a continuación, se realizará el ejercicio de identificar si existe un derecho de propiedad respecto de los bienes identificados en la primera sección. Estos son: los datos, las bases de datos creadas y utilizadas para extraer conocimiento de valor en la nueva economía digital y los conocimientos o resultados obtenidos de técnicas o tecnologías de procesamiento de datos. Asimismo, se abordarán los límites que impone el marco normativo vigente en materia de protección de datos personales cuando existe algún derecho de propiedad reconocido sobre las bases de datos y conocimientos extraídos a través de su procesamiento.

\section{La naturaleza jurídica y los derechos sobre los datos en el derecho chileno}

Cuando el Código Civil regula los bienes en el libro II comienza estableciendo una summa divisio, al señalar que los bienes consisten en "cosas" 
corporales e incorporales. Luego, indica que los bienes corporales consisten en todas aquellas cosas que "tienen un ser real y pueden ser percibidas por los sentidos, como una casa y un libro"; y, los bienes incorporales, son los que "consisten en meros derechos, como los créditos y las servidumbres activas". Sin embargo, ¿qué pasa cuando existe "algo", que no tiene un ser corporal, ni tampoco consiste en un derecho propiamente tal? En este punto, pareciera que se produce un limbo jurídico, en el cual existen bienes que son imposibles, o al menos muy difíciles, de clasificar.

Esto es lo que precisamente ocurre con los datos. Pues, como se indicó en la primera sección, los datos no son su soporte físico, ni su contenido, sino una:

"Realidad propia y diferenciada: es la representación lógica computable del contenido, susceptible de ser copiada de forma idéntica en otro dispositivo" ${ }^{44}$.

Por lo mismo, pese a que los datos sí poseen una dimensión física, basada en el tipo de soporte en el cual se manifieste dicha información en un momento determinado, no se debe confundir su dimensión corporal, con esta entidad nueva y distinta, que surge cuando existe una representación simbólica de un contenido ${ }^{45}$.

En efecto, en este punto es indispensable recordar que desde un punto de vista técnico, los "datos son información, y la información es incorpórea, ubicua y cambiante" ${ }^{46}$. Es decir, no ocupan un espacio físico determinado, aunque se encuentren alojados en dispositivos electrónicos o analógicos y, pueden ser duplicados o replicados un sin número de veces, mientras se mantenga la misma identidad de la información en todas estas representaciones simbólicas ${ }^{47}$.

Entonces, retomando la regulación el Código Civil, es evidente que se está ante un objeto difícil de clasificar, porque los datos son distintos a su dimensión corpórea e incorpórea y, como tal, no califican para ser considerados como "cosas". Pues, como ya se explicó una cosa corporal debe tener un ser real, capaz de ser percibido con los sentidos o, bien, puede ser incorporal si consiste en un derecho. Sin embargo, el dato no es ni uno ni lo otro, porque es una representación simbólica de la realidad independiente de su soporte.

${ }^{44}$ Torre de Silva y López de Letona (2019), p. 831.

${ }^{45}$ Op. cit., p. 836.

${ }^{46}$ Ibid.

${ }^{47}$ Ibid. 
Atendido lo anterior, es conveniente señalar que, tanto en la doctrina nacional como extranjera, han surgido distintas reflexiones destinadas a buscar una forma de clasificar aquellos "objetos" que sin ser cosas, merecen protección jurídica. Para ello, se propone distinguir entre los conceptos "cosa" y "bien", aunque esto sea un ejercicio que presenta un grado de dificultad mayor en el derecho nacional, considerando que ninguno de los dos conceptos se encuentra expresamente definido en el Código Civil.

En la doctrina, la distinción entre la noción "bien" y "cosa" se sustenta en que esta última se define a como "todo elemento que ocupa un lugar en el espacio; es decir, que tiene una corporalidad sensible" ${ }^{48}$. Por lo mismo, se insiste en el obstáculo de aplicar este concepto a aquellas entidades que no gozan de corporalidad o materialidad, como las energías o:

"Producciones del talento o del ingenio, cuya importancia no cesa de aumentar por el desarrollo de las creaciones científicas y tecnológicas y, particularmente, con el desenvolvimiento de la computación" 49 .

Por otro lado, otro sector de la doctrina ha propuesto conceptualizar la noción "cosa" en contraposición al concepto de persona. En consecuencia, sería "cosa todo lo que no es persona" ${ }^{50}$. Empero, esta conclusión no está exenta de críticas, porque según distintos autores, es perfectamente posible imaginar "cosas" que no son personas, pero cuya calificación bajo la noción "cosa" tampoco es conveniente como, por ejemplo, órganos u otras partes del cuerpo humano ${ }^{51}$.

En el derecho comparado, esta misma discusión sobre el alcance de las nociones "bien y "cosa" ha arribado a conclusiones distintas, aunque existe una idea predominante que señala que "todas las cosas son bienes, pero hay bienes que no son cosas" ${ }^{52}$. Es decir, la noción de bien es más amplia que el de cosa, ya que incluye objetos sin corporalidad como las energías, creaciones del intelecto humano y otros bienes jurídicos, como la protección del ambiente o atributos de la personalidad. Con todo, evidentemente la discusión es compleja, porque también se relaciona con la capacidad de un bien, sea material o inmaterial, de ser apropiable, comerciable o protegido por el ordenamiento jurídico en caso de lesión.

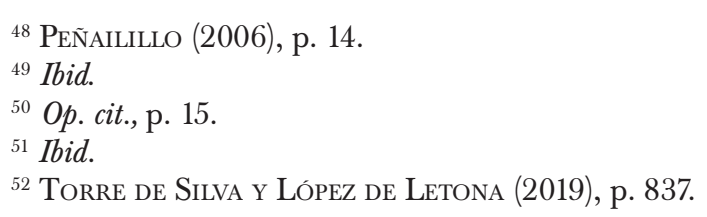


En el derecho chileno, parte de la doctrina ha señalado que los bienes son "objetos" que "prestando una utilidad para el hombre, son susceptibles de apropiación" ${ }^{3}$. En otras palabras, el concepto de bien puede consistir en algo inmaterial, que presta una utilidad y es susceptible de ser apropiable. Con todo, también existe un sector doctrinario que habla de bienes inmateriales, para referirse a los derechos intelectuales que pueden existir sobre creaciones del espíritu o de la mente que no sean derechos ${ }^{54}$.

Ahora bien, en este punto es preciso señalar que, pese a que no existe una definición unánimemente aceptada para los conceptos "bien" y "cosa" en el derecho civil, sí es relevante reconocer que existe una categoría que es más amplia que la de objetos materiales y los meros derechos, que permite clasificar a los datos como bienes. Por lo mismo, solo para efectos del presente artículo, se ha decidido adoptar la definición de 'bien' propuesta por Javier Torre de Silva y López de Letona. Esta definición indica:

"Todo aquello que puede ser objeto de lesión indemnizable por vía de responsabilidad extracontractual es un bien jurídico, sea o no cosa, y sea o no apropiable en sentido técnico-jurídico" ${ }^{55}$.

Es decir, se adopta el criterio de distinción que reconoce a los bienes como un todo, compuesto por distintos elementos, como las cosas corporales, incorporales y otras categorías de cosas "inclasificables" ${ }^{56}$.

Por lo tanto, se concluye que un dato no es una cosa, sino una entidad que se constituye como un bien jurídico distinto a su soporte y, como tal, merece ser analizado para determinar si sobre este puede ejercerse un derecho real de dominio, considerando que dicha entidad no puede ser clasificada como cosa corporal o incorporal, conforme a lo dispuesto en el Código Civil. Asimismo, tomando en consideración que un dato es distinto al contenido que en él se expresa, también es necesario reconocer que dicha información es un bien jurídico distinto del dato mismo y, por tanto, puede ser objeto de protección mediante un derecho de propiedad intelectual o industrial, si emana de una producción del talento o ingenio; o, bien, puede ser resguardado por las normas de tutela de datos personales, si consiste en una información que identifica o permite identificar a una persona natural.

Por lo tanto, a continuación, se analizará si es posible determinar que los datos como bienes jurídicos son susceptibles a un derecho de propie-

\footnotetext{
${ }^{53}$ Peñalillo (2006), p. 17.

${ }^{54}$ Alessandri, Somarriva y Vodanic (2005), p. 29.

${ }^{55}$ Torre de Silva y López de Letona (2019), p. 838.

${ }^{56}$ GuZMán (2019), p. 56.
} 
dad en el ordenamiento jurídico chileno, para posteriormente resolver si existen regulaciones complementarias a considerar en esta materia. Para ello, primero se estudiará el derecho de propiedad establecido en nuestra Carta Fundamental actual y, luego lo establecido sobre este derecho en el Código Civil.

\section{a) Los datos y la regulación de la propiedad en la Constitución}

Para comenzar, es necesario aclarar que la Carta Fundamental en el art. 19, n. 23 consagra la libertad para adquirir toda clase de bienes (no cosas). En efecto, la norma establece que se asegura a todas las personas:

"La libertad para adquirir el dominio de toda clase de bienes, excepto aquellos que la naturaleza ha hecho comunes a todos los hombres o que deban pertenecer a la Nación toda y la ley lo declare así. Lo anterior es sin perjuicio de lo prescrito en otros preceptos de esta Constitución".

En este sentido, el objetivo era no solo proteger el derecho de propiedad adquirido, sino, también, "el libre acceso a la propiedad"57. Por lo 122 mismo, el fin de esta garantía era asegurar que cualquier persona pudiera hacer ingresar a su dominio privado, bajo:

"Cualquier título lícito toda clase de bienes, sean muebles o inmuebles, corporales o incorporales y, en general, todas las cosas susceptibles de ser incorporadas a un patrimonio personal y proteger así a las personas de actos legislativos o de autoridad que las excluyan de este libre acceso a una categoría de bienes ${ }^{" 58}$.

No obstante, los únicos límites a esta garantía estarían dados por aquellos bienes que:

i) La naturaleza ha hecho comunes a todos los hombres o

ii) Deban pertenecer a la nación toda, cuando la ley de quórum calificado lo declare así.

Es decir, esta libertad no puede ser coartada por una ley común.

Entonces, es posible concluir que, al menos desde un punto vista constitucional, para determinar si los datos pueden ser libremente adquiridos por cualquier privado, es necesario resolver si por su naturaleza, los son "comunes a todos los hombres" o debiesen pertenecerle a la nación

${ }^{57}$ Cruz-Coke (2009), p. 517.
${ }^{58}$ Op. cit., p. 519. 
toda, en cuyo caso, además, debiese existir una ley de quórum calificado que excluya el ejercicio de esta libertad de adquisición. En caso de que no se cumplan ninguna de estas restricciones y se estime que son objetos susceptibles de ser protegidos por el derecho de propiedad, podríamos resolver que estos bienes pueden ser sujetos apropiación e ingresar al patrimonio de cualquier persona.

En Chile, a diferencia de otras legislaciones, no existe una limitación, regulación o reflexión específica en materia de datos que permitan zanjar fácilmente cómo aplicar esta garantía constitucional. Sin embargo, considerando el inicio del proceso constituyente y que, en otras legislaciones, sí se ha avanzado en la discusión sobre estos temas, resulta interesante plantear cómo se ha desarrollado la discusión sobre el papel de los datos en la sociedad de la información, específicamente en el marco de la economía digital y el principio de acceso libre a la información disponible en internet.

En Estados Unidos es posible identificar dos tendencias opuestas en la discusión sobre un posible de derecho o facultad de apropiación de los datos. Por una parte, se desarrolla una tesis que propone un derecho de propiedad sobre los datos -incluso de carácter personal- y sobre su contenido, en virtud de la existencia de un interés susceptible de tráfico jurídico. Por otra parte, existe una postura que distingue tres casos distintos, primero la propiedad sobre el dato mismo, segundo la propiedad sobre el contenido de los datos y, un tercer caso, donde no cabe propiedad sobre el dato ni su contenido, aunque sea posible tutelar el uso de dicha información en forma indirecta, gracias a conceptos como competencia desleal u otros ilícitos ${ }^{59}$. En este último supuesto esta tesis busca fortalecer el acceso libre de la información, cuando no exista un derecho individual y exclusivo sobre el dato o el contenido del mismo ${ }^{60}$.

Sin perjuicio que esta discusión no es idéntica a la disponibilidad de ciertos contenidos en internet, es evidente que existe una relación directa entre el concepto de apropiación de los datos con el uso de su contenido, porque al reconocer un derecho de propiedad sobre una representación simbólica de la realidad, el titular del dato sí podría excluir a terceros del uso de dicha información, incluso una vez publicada en fuentes como internet ${ }^{61}$.

Por otro lado, en Europa este debate también ha adquirido bastante relevancia. Especialmente debido a la construcción de la estrategia de un mercado único digital, donde básicamente existe una tendencia a eliminar

\footnotetext{
${ }^{59}$ TorRe de Silva y LóPez de Letona (2019), p. 842.

${ }^{60} \mathrm{Ibid}$.

${ }^{61}$ Ibid.
} 
los obstáculos a la libre circulación de los datos, creando un marco político y jurídico que permita remediar la incerteza generada por las nuevas tecnologías de datos ${ }^{62}$. Para ello, se analizan los siguientes principios:

"La libre circulación de datos; el acceso y la transferencia en relación con los datos generados por máquinas; la responsabilidad y la seguridad en el contexto de las tecnologías emergentes; y la portabilidad de los datos no personales, la interoperabilidad y las normas" ${ }^{3}$.

Para efectos del presente artículo, se destaca el valor que se le ha otorgado en la Comisión Europea al libre acceso a los datos y a su transferencia, sobre la base de que:

"Los agentes del mercado necesitan tener acceso a conjuntos de datos amplios y diversos. Sin embargo, esto resulta más difícil de lograr si los productores de los datos los reservan para sí mismos $\mathrm{y}$, en consecuencia, los datos se analizan en compartimentos estanco" ${ }^{64}$.

Por consiguiente, retomando lo señalado respecto a la garantía constitucional sobre la libertad de adquirir toda clase de bienes, es posible concluir que, en principio, el derecho chileno permitiría apropiarse y hacer ingresar al patrimonio de una persona ciertos datos que cumplen con determinadas características. Sin embargo, considerando la regulación del Código Civil y la propiedad intelectual, es difícil imaginar cómo se podría ejercer ese derecho de dominio sobre bienes inmateriales sin regulación especial.

Asimismo, es posible argumentar que la sociedad chilena valora el libre acceso de la información y, por lo mismo, los datos sobre los cuales no recae otro tipo de derecho o protección -como la propiedad intelectual o los datos personales-, efectivamente no es posible ejercer un derecho de dominio. Pues, estos datos, como bienes jurídicos independientes de su contenido, les pertenecen a todos los hombres. No obstante, ante todo, es una decisión política mientras no exista una regulación especial, porque el tratamiento o valor de los datos donde no existe un derecho de propiedad intelectual o protección especial, por tratarse de un dato personal, está íntimamente relacionado con otros principios como el libre acceso a la información o, incluso, la libre competencia.

\footnotetext{
${ }^{62}$ Comisión Europa (2017), p. 5.

${ }^{63}$ Ibid.

${ }^{64}$ Op. cit., p. 9.
} 
De hecho, en caso de acogerse una interpretación similar a la europea -donde prima el libre acceso a los datos- probablemente es posible concluir que no cabe propiedad sobre lo datos "brutos" u primarios, salvo cuando estos sean, al mismo tiempo, una obra protegida por derechos de autor ${ }^{65} \mathrm{y}$, cuando estos se encuentren publicados en fuentes de libre acceso al público, no se podrá ejercer ningún derecho que permita excluir de su uso a terceros. Empero, si se estima que los datos no pertenecen a todos los hombres y que son bienes -una noción distinta a la cosa-, no habría ninguna buena razón para no aceptar que estos pueden ser adquiridos e ingresados al patrimonio de una persona, ya que la garantía constitucional no distingue el tipo de bien que puede ser adquirido por un derecho real de dominio.

Sin perjuicio de lo anterior, cuando se analiza el art. 19 n. ${ }^{\circ} 24$ de la Constitución, se presenta un nuevo inconveniente, porque a diferencia de la disposición anterior, en este artículo sí existe una aparente ampliación sobre el objeto del derecho de propiedad, ya que no se limita a hablar de cosas, sino establece que este derecho se consagra "en sus diversas especies sobre toda clase de bienes corporales o incorporales". Por consiguiente, nuevamente es necesario cuestionar si al hablar de bienes incorporales nuestra Carta Fundamental está pensando en ofrecer protección mediante un derecho de dominio sobre cualquier tipo de bien inmaterial -esto es, no solo derechos sino otras categorías como energía o creaciones intelectuales- considerando que en el Código Civil, como se expondrá en la siguiente sección, existe una diferencia entre el derecho de dominio sobre la cosas corporales e incorporales.

En este punto, cabe precisar que la doctrina constitucional señala que en esta disposición de la Constitución, se tomó la decisión consciente de incluir en la garantía la protección de la propiedad tanto de bienes corporales e incorporales ${ }^{66}$. En efecto, esta es la razón por la cual "se elevó a un rango constitucional la disposición contenida en el artículo 583 del Código Civil” ${ }^{67}$ y, en consecuencia, la "Constitución ampara bienes materiales (muebles o inmuebles) y derechos y acciones en su integridad"68.

Sin embargo, desde el punto de civil, se ha resuelto que la expresión 'bienes' en la Constitución, más que extender el sentido a todo tipo de

${ }^{65}$ En este punto, cabe destacar que un dato puede ser obtenido de una obra que está protegida por derechos de autor. Por ejemplo, un archivo, un escrito, una noticia, un video, una fotografía, etc. Con todo, es relevante destacar que la obra debe haber sido creada por una persona natural -nunca una máquina, algoritmo o dispositivo interconectado-, y que la representación simbólica de la información constatada en el dato, sea una expresión original.

${ }^{66}$ Cruz-Coke (2009), p. 524.

${ }^{67}$ Ibid.

${ }^{68}$ Ibid. 
cosas, sean o no clasificables bajo el concepto de cosa corporal o incorporal, limita el universo de objetos protegidos por el derecho de propiedad a aquellos bienes inmateriales que también sean $\operatorname{cosas}^{69}$. En ese sentido, se ha resuelto que la "Constitución no creó un concepto nuevo en el derecho chileno ni amplió la noción de cosa incorporal que se observa en el Código Civil" ${ }^{\prime 0}$, porque los bienes consisten en cosas corporales e incorporales y que sobre las cosas incorporales -no bienes- existe una especie o tipo de propiedad, es posible resolver que la expresión "bienes incorporales" en la Carta Fundamental "alude a derechos y sólo a derechos, aunque no todos los derechos" "11. En efecto, lo anterior significa que en el derecho chileno todas las cosas son bienes, pero no todos los bienes son cosas. Por ende, la expresión "bienes incorporales" está indicando a conceptos que "siendo cosa incorporal, es la vez bien, y sólo se está excluyendo a algo que, siendo cosa incorporal, no es bien" $"$.

Ahora bien, en virtud de lo expuesto, es necesario cuestionarse si, además de la limitación antes mencionada, es posible concluir que la intención del legislador es que exista un derecho de propiedad sobre bienes inmateriales que son distintos a los meros derechos o aquellos que sean producidos como una creación intelectual. Esto, porque, por una parte, está la definición de las cosas incorporales en el derecho civil -como meros derechos- $y$, por otra parte, también existe una garantía constitucional distinta para las creaciones intelectuales. En efecto, el art. 19 n. ${ }^{\circ} 25$ que asegura:

"La libertad de crear y difundir las artes, así como el derecho del autor sobre sus creaciones intelectuales y artísticas de cualquier especie, por el tiempo que señale la ley y que no será inferior al de la vida del titular".

En este contexto, es posible concluir que, desde un punto de vista constitucional, no parece existir un marco normativo que permita apropiarse de los datos propiamente tal, pues consisten en bienes jurídicos incorpóreos, fuera del alcance del derecho de propiedad. No obstante, en el derecho chileno, sí existe un derecho de propiedad, con matices, como se expondrá a continuación, cuando el contenido del dato es resultado de una creación intelectual humana.

Por ende, para responder a la pregunta inicial referida a la posibilidad de reconocer un derecho de propiedad respecto de los datos "brutos"

\footnotetext{
${ }^{69}$ GuZMán (2019), p. 273.

${ }^{70}$ Ibid.

${ }^{71}$ Op. cit., p. 275.

72 Op. cit., p. 274.
} 
o primarios -sobre los cuales no recae una protección jurídica especial respecto a su contenido, como propiedad intelectual, industrial o datos personales-, es necesario distinguir si se está hablando de los datos propiamente tal o sobre la información o contenido en dicha entidad. Pues, porque sobre los primeros no existe un derecho de dominio reconocido en el ámbito constitucional, pero sobre los segundos, sí es posible remitirse a un estatuto de propiedad distinto, como lo son los derechos de autor o propiedad industrial.

Esta conclusión, como se verá a continuación, es plenamente coherente con la regulación del derecho real de dominio en el Código Civil, ya que este derecho depende de cómo se clasifican las cosas al inicio del libro II.

b) Los datos y la regulación del derecho real de dominio en el Código Civil

El Código Civil chileno define el derecho de dominio como aquel "derecho real en una cosa corporal, para gozar y disponer de ella arbitrariamente; no siendo contra la ley o contra derecho ajeno"73. Es decir, siguiendo la tradición romana, para que este derecho sea reconocido, es necesario que recaiga sobre una cosa material que sea capaz de ser percibida por los sentidos $^{74}$.

Sin embargo, como se puede apreciar del análisis previamente expuesto, los datos difícilmente podrían ser clasificados como cosas corporales, pese a que su soporte sí les permite "adquirir" una corporalidad analógica o digital. Por lo mismo, pese a que el dato es distinto a su soporte, se puede concluir que sobre la materialidad en la que se expresa el dato es posible ejercer un derecho de dominio, porque tiene un ser real que puede ser percibido por los sentidos. Esto, sin perjuicio que el contenido del dato individualmente considerado no quedará protegido por ese derecho real por su dimensión incorpórea.

Atendido lo anterior, cabe la pregunta: ¿̇l Código Civil admite algún tipo de propiedad sobre los datos propiamente tales y, más aún, sobre su contenido? En general, la respuesta es no, porque el dato como entidad distinta a su soporte y contenido sería un bien inmaterial diferente a un derecho y a una producción del talento o del ingenio ${ }^{75}$, cuya regulación se encuentra en leyes especiales.

Dicho de otro modo, en virtud de que los datos no consisten en una cosa incorporal no se podría ejercer sobre ellos una "especie de propie-

\footnotetext{
${ }^{73}$ Art. 582 del Código Civil.

${ }^{74}$ Alessandri, Somarriva y Vodanic (2005), p. 65.

${ }^{75}$ Art. 584 del Código Civil.
} 
dad"76 porque no son derechos ${ }^{77} \mathrm{y}$, por ende, no se les podría aplicar una relación similar al derecho de propiedad, como la que existe para este tipo de cosas en el derecho civil. Asimismo, como existe un conjunto de datos que no son resultado de una creación intelectual humana -los datos "primarios" o aquellos que son resultado de un procesamiento de máquina- tampoco sería posible clasificarlos como bienes inmateriales protegidos por derechos intelectuales ${ }^{78}$, cuya regulación se establece en normas especiales de propiedad intelectual (o industrial), conforme a lo establecido en el art. 584 del Código Civil.

En consecuencia, para el derecho civil lo esencial para establecer si existe algún tipo de derecho sobre los datos, sería distinguir si en estos se representa simbólicamente un contenido o información especial que, coincidentemente, consista en una creación intelectual protegible por la Ley de Propiedad Intelectual o Industrial. Pues, solo cuando se cumplan los requisitos de las creaciones intelectuales o artísticas, se puede concluir que consiste en un bien material protegido por un derecho de "propiedad" regulado en una norma especial, cuyo alcance también presenta matices respecto del derecho real de dominio regulado en la legislación común ${ }^{79}$.

Ahora bien, retomando la importancia de distinguir el dato de su contenido, cabe recordar lo desarrollado en la sección anterior, sobre los requisitos de las obras protegidas por derechos de autor. En efecto, estos deben ser producidos por una persona natural -la norma habla de un autor, en consecuencia, quien produzca el dato derivado no puede ser una máquina o algoritmo que permita generar este nuevo dato sobre otro dato primario o derivado, sino únicamente una persona humana- $y$, que estos datos, sean una expresión original resultante de una obra de la inteligencia de los dominios literarios, artísticos o científicos.

Por esta razón, no cabe más que concluir que, en el marco normativo vigente, existe un conjunto de datos, principalmente conformado por los datos brutos o primarios que no pueden ser clasificados como cosas según el Código Civily tampoco como una producción del talento o ingenio de un autor. En consecuencia, sobre estos no se podría ejercer un derecho de propiedad, porque no existe una figura legal que regule un derecho dominio sobre bienes inmateriales que no sean resultado del ingenio o talento de una persona. De hecho, como se expuso, solo existe un derecho real dominio sobre una cosa corporal o las creaciones originales del intelecto humano ${ }^{80} \mathrm{y}$, una especie de propiedad cuando la cosa sea un derecho.

\footnotetext{
${ }^{76}$ Art. 583 del Código Civil.

77 Art. 582 del Código Civil.

${ }^{78}$ Peñallillo (2006), p. 14.

${ }^{79}$ Guzmán (2019), p. 64.

${ }^{80}$ Art. 582 del Código Civil.
} 
Por consiguiente, para determinar si existe algún tipo de derecho sobre los datos, será necesario descartar su protección como entidad individualmente considerada, aunque sea posible otorgar algunos mecanismos de protección asociados a su contenido, como ocurre en el caso de las creaciones del talento o ingenio humano. Pues, si estos consisten en representaciones simbólicas de una creación literaria, artística o científica, es posible atribuir a su autor $-\mathrm{O}$ a quien detente los derechos patrimoniales de la obra- derechos autónomos que permiten excluir de su uso a terceros. Asimismo, se podrán concebir mecanismos de tutela vinculados con la confidencialidad del contenido del dato, pero jamás un derecho real de dominio, con efecto erga omnes, que permita recuperar -reivindicardicho dato e información en manos de cualquier tercero que lo detente sin permiso o autorización de su "dueño".

Atendido lo anterior, es necesario referirse al alcance del concepto 'propiedad' establecido en la Ley n..$^{\circ} 17336$ y Ley n. ${ }^{\circ} 19039$, para que los nuevos modelos de negocios utilicen las herramientas jurídicas disponibles en el ordenamiento chileno y así proteger los nuevos activos intangibles que se generen en técnicas o disciplinas como la ciencia de datos.

c) La propiedad intelectual sobre los datos derivados, las bases de datos y los conocimientos generados por la ciencia de datos

Para comenzar, es necesario precisar que, desde la perspectiva del derecho civil, se cuestiona si el concepto de propiedad intelectual o industrial coincide con el derecho real de dominio regulado en el Código Civil. En efecto, entre los distintos elementos a considerar en esta comparación se pueden mencionar las siguientes distinciones:

i) El derecho sobre obras intelectuales o de propiedad industrial son esencialmente temporales, a diferencia del derecho real de dominio;

ii) La propiedad intelectual o industrial realmente consiste en un derecho exclusivo de "ilimitada reproducción o producción", el cual no coincide con el derecho de exclusividad que otorga la propiedad clásica;

iii) La propiedad intelectual o industrial tampoco admite ejercer una facultad de disposición y goce propiamente tal;

iv) Los derechos de propiedad son eminente territoriales, lo cual no se observa en el derecho de dominio sobre cosas corporales ${ }^{81}$.

Por consiguiente, e independiente de que el foco de este artículo está en identificar si el dato -individualmente considerado- es una creación

${ }^{81}$ GuZMán (2019), p. 64. 
intelectual, literaria, artística o científica; o, bien, simplemente un "mero continente de información", para determinar si sobre estos bienes inmateriales existen derechos de "propiedad" conviene tener presente que, incluso en estos supuestos, existen matices en la noción de dominio empleada en las normas especiales.

Con todo, para efectos del presente trabajo, también es necesario reiterar que los datos provienen de diversas fuentes y pueden adoptar distintas formas, porque consisten en una representación simbólica de la realidad. En ese sentido, por sí mismos pueden consistir en obras protegidas por la Ley n. ${ }^{\circ} 17336$, como: un libro, artículo, escritos, conferencias, discursos, periódicos, revistas, fotografías, videos, ilustraciones, etc. ${ }^{82} \mathrm{y}$, como tal, pueden ser objeto de protección de derechos de autor, incluso antes de su procesamiento.

De igual manera, es relevante reiterar el concepto doctrinario de autor, ya que pese a no estar definido en la norma, esta expresión siempre ha sido asociada a una persona natural -no máquina, algoritmo o tecnologías como el Big Data-, porque la tradición jurídica chilena supone que la creación intelectual es resultado de una actividad humana. Por lo mismo, se dice que, mediante los derechos de autor, se resguarda "la vinculación de la persona con su obra, como proyección de su personalidad"83. Por lo tanto, todos los datos recopilados y procesados por dispositivos, como sensores, smartwatches, smartphones o algoritmos, probablemente no merecerán protección en el derecho chileno como obras intelectuales, porque su obtención difícilmente puede atribuirse a la "creación intelectual" de un "autor".

Asimismo, los datos obtenidos de los datos, es decir, los "datos derivados", también deberán ser analizados bajo este criterio, porque este tipo de bienes, individualmente considerados, pueden estar sujetos a la protección de los derechos de autor si son "generados" como una creación intelectual de una persona natural expresada en una forma original.

De este modo, y como conclusión a todo lo expuesto, el Big Data, comprendido como:

"Datos nuevos obtenidos de otros masivos, previamente anonimizados, susceptibles de ser tratados con independencia de la fuente de la que proceden y con una finalidad diferente" ${ }^{84}$

o los datos producidos por tecnologías como la I.A., no podrán ser protegidos por un derecho de propiedad intelectual según lo dispuesto en el

\footnotetext{
${ }^{82}$ Art. 3 de la Ley n. ${ }^{\circ} 17336$ de 1970.

${ }^{83}$ Walker (2020), p. 96.

${ }^{84}$ Torre de Silva y López de Letona (2019), p. 832.
} 
marco normativo vigente, porque no son considerados producciones del talento o ingenio de un autor humano. Por lo tanto, existe un inmenso conjunto de resultados y conocimientos que se encuentran expresamente excluidos de categorías como cosas corporales, incorporales y creaciones intelectuales y, como tal, no tienen protección bajo el concepto de propiedad, ni siquiera con "matices", como ocurre con la denominada propiedad intelectual o industrial.

Para efectos del presente artículo es relevante destacar que el análisis expuesto es igualmente aplicable a los otros tipos de activos en la economía de datos, estudiados en la primera sección, como las bases de datos y los contenidos de los datos, ya que solo cuando estas reúnen todos los requisitos establecidos en la Ley n. ${ }^{\circ} 17336$, es posible protegerlos mediante derechos de autor ${ }^{85}$. Ahora bien, también es relevante precisar que las bases de datos son creaciones distintas a sus componentes. Por ende, la legislación enfatiza que la tutela otorgada a través de la propiedad intelectual no alcanza a los:

"Datos o materiales en sí mismos, y se entiende sin perjuicio de cualquier derecho de autor que subsista respecto de los datos o materiales contenidos en la compilación" ${ }^{86}$.

En consecuencia, es posible concluir que, si bien no existe propiedad sobre el dato propiamente tal, sí puede existir protección al contenido del dato y sobre las creaciones que se generen para realizar un estudio u organización de agrupaciones de estos, como ocurre en el caso de las bases, susceptibles de tutela por derechos de autor.

Por último, aunque no menos importante, en cuanto a los conocimientos extraídos por el estudio de los datos a través de la ciencia datos, es relevante destacar que en la medida que estos cumplan con los requisitos de las obras protegibles por derechos de autor, se deberán interpretar como un activo nuevo y distinto de los datos y las bases estudiadas, porque es un resultado, una predicción elaborada sobre la base de la información examinada. Sin embargo, nuevamente se presenta el problema de que en la actualidad la ciencia de datos generalmente produce dichos resultados a través algoritmos y máquinas programadas. Por ende, si no es posible

${ }^{85}$ En este punto, es interesante precisar que en Europa se está buscando incentivar la protección de las bases de datos que no cumplen con los requisitos de los derechos de autor a través de un nuevo derecho sui generis. Esto, dado que en la nueva economía de datos se ha identificado la necesidad de considerar estas bases como "dignas de protección por el esfuerzo e inversión destinados a la obtención, verificación y presentación de los datos". Romeu i Cónsul (2019), p. 199.

${ }^{86}$ Art. 3, n. ${ }^{\circ} 17$ de la Ley n. ${ }^{\circ} 17336$ de 1970. 
explicar o encausar estos resultados a una creación intelectual de una persona natural -aunque sea asistida por mecanismos tecnológicos- nos enfrentamos a la complicación de intentar protegerlas vanamente mediante la propiedad intelectual, aunque su "autor" no sea una persona natural.

Para enfrentar este desafío, es posible señalar que los datos, las bases de datos y los conocimientos obtenidos del estudio de estos recursos, también pueden ser protegidos por un derecho de propiedad industrial, sin importar si estos son generados por un autor, un algoritmo o Big Data. Pues, el derecho chileno también consagra en la Ley n. 19039 el denominado "secreto empresarial", que se define como:

"Todo conocimiento sobre productos o procedimientos industriales, cuyo mantenimiento en reserva proporciona a su poseedor una mejora, avance o ventaja competitiva" ${ }^{\text {}}$.

Es decir, en la medida que el contenido de los datos se mantenga en reserva y pueda proporcionar una ventaja competitiva, se crea un activo distinto a los datos individualmente considerados, bases de datos o conocimientos generados del estudio de los datos, denominado secreto empresarial sobre el cual se puede ejercer un derecho de propiedad industrial. Sin perjuicio de que es evidente que esta protección recae en el contenido, en la información misma, no en los bienes inmateriales identificados. Por ello, será necesario adoptar todas las medidas jurídicas para imponer deberes de confidencialidad y evitar la divulgación no autorizada de la información contenida en los datos, bases o conocimientos que componen el secreto empresarial.

Atendido lo anterior, se puede concluir que en el derecho chileno los datos, como bienes jurídicos analizados en tanto entes independientes de su contenido, no gozarán de protección por vía de un derecho real de dominio. Sin embargo, existen contenidos o creaciones basadas en datos, que sí gozan de tutela bajo un derecho de propiedad, ya que son creaciones intelectuales protegidas por derechos de autor, según lo establecido en la Ley . $^{\circ} 17336$ o derechos de propiedad industrial, regulados en la Ley n. ${ }^{\circ} 19039$.

Ahora bien, la última pregunta que cabe formularse sobre las regulaciones aplicables a los negocios desarrollados en la nueva economía basada en datos, es si es compatible el derecho de propiedad intelectual sobre el contenido de los datos, bases de datos o conocimientos que han sido obtenidos por las nuevas técnicas o disciplinas, con la protección de los datos personales consagrada en la Carta Fundamental. Pues, como se

${ }^{87}$ Art. 86 de la Ley n. ${ }^{\circ} 19039$ de 1991. 
explicó en la primera sección del artículo, en muchas ocasiones el dato más valioso en la economía digital es aquel que contiene información que identifica o permite identificar a una persona natural y, justamente ese contenido es lo que gatilla la aplicación de una norma especial distinta.

Por consiguiente, a continuación, se desarrollará el alcance de la garantía constitucional referida a la protección de datos personales y cómo esta puede convivir de manera armónica con los derechos de propiedad sobre los distintos activos intelectuales en esta sección.

\section{Protección de datos personales versus los derechos de propiedad de los nuevos activos de la economía digital}

Para comenzar a analizar esta materia es necesario referirse al art. 19 n. ${ }^{\circ} 4$ de la Constitución, que consagra el derecho a la protección a los datos personales, especificando que "el tratamiento y protección de estos datos se efectuará en la forma y condiciones que determine la ley". En virtud de esta disposición, es evidente que existe un límite de rango constitucional al tratamiento de datos en virtud de su contenido, ya que cuando se trata de datos personales, la forma y condiciones de este tratamiento deben hacerse en los términos que determine la ley correspondiente.

Actualmente, la ley que establece el límite, la forma y condiciones de este tratamiento es la Ley n. ${ }^{\circ} 19628$. De hecho, en el art. 1 inciso final señala:

"Toda persona puede efectuar el tratamiento de datos personales, siempre que lo haga de manera concordante con esta ley y para finalidades permitidas por el ordenamiento jurídico. En todo caso deberá respetar el pleno ejercicio de los derechos fundamentales de los titulares de los datos y de las facultades que esta ley les reconoce"

y se establece que el tratamiento de datos solo puede realizarse cuando la ley o el titular -debidamente informado- autoriza o consiente expresamente a ello ${ }^{88}$.

De manera adicional, la Ley n. ${ }^{\circ} 19628$ establece un concepto de tratamiento de datos personales lo bastante amplio para incluir prácticamente cualquier operación, desde la recolección hasta la organización de uno o más datos personales en una base de datos. En efecto, se entiende por tratamiento de datos personales:

${ }^{88}$ Art. 4 de la Ley n. ${ }^{\circ} 19628$ de 1999. 
"Cualquier operación o complejo de operaciones o procedimientos técnicos, de carácter automatizado o no, que permitan recolectar, almacenar, grabar, organizar, elaborar, seleccionar, extraer, confrontar, interconectar, disociar, comunicar, ceder, transferir, transmitir o cancelar datos de carácter personal, o utilizarlos en cualquier otra forma" ${ }^{" 89}$.

Por lo mismo, para efectos del presente trabajo, es necesario destacar que cualquier actividad o estudio sobre datos personales que se realice en el marco de la ciencia de datos, requerirá cumplir con todos los principios y requisitos en la Ley n. $^{\circ} 19628$ (o la regulación que en el futuro la reemplace).

Ahora bien, aunque en esta oportunidad no se tratarán en específico las condiciones de la autorización y los principios que rigen en esta materia, porque el objeto de estudio son los límites que se pueden imponer en la nueva economía basada en datos cuando se realice un tratamiento de datos personales, lo relevante es recordar que en el ordenamiento jurídico chileno existe un responsable del tratamiento, quien toma las decisiones sobre las operaciones de procesamiento y responde ante los titulares por las condiciones del tratamiento de sus datos personales. Este puede ser una persona que recolecta los datos, quien elabora una base, ordena extraer conocimiento valioso de un conjunto de datos o el que realiza ciencia de datos sobre bases ya utilizadas por otros actores del mercado.

Por otro lado, la normativa vigente les concede a los titulares los denominados derechos $\mathrm{ARCO}^{90}$, los cuales les permiten exigir toda la información relacionada sobre el tratamiento de sus datos personales al responsable, rectificarlos en caso de que la información sea inexacta, equívoca o incompleta, eliminarlos de la operación de tratamiento e, incluso, oponerse a un determinado tratamiento de datos personales. En consecuencia, existen derechos de los titulares que se encuentran vigentes durante todo el tratamiento de sus datos personales, los cuales pueden interrumpir o hacer cesar un tratamiento de los datos que contengan información que identifique o permita identificar a su titular.

Atendido lo anterior, es posible concluir que en el caso de que exista una suerte de conflicto entre un derecho de propiedad sobre los activos generados en los modelos de negocios basados en el estudio de los datos y los derechos de los titulares de los datos personales, pareciera primar, debido a su consagración constitucional y regulación en la Ley n. ${ }^{\circ}$ 19628, los derechos de los titulares del tratamiento. Pues, el objetivo del derecho consagrado en el art. 19 n. ${ }^{\circ} 4$ de la Carta Fundamental, era dar una respuesta jurídica que:

${ }^{89}$ Art. 2, letra o) de la Ley n. ${ }^{\circ} 19628$ de 1999.

${ }^{90}$ Art. 12 de la Ley n. ${ }^{\circ} 19628$ de 1999. 
"Permitiera controlar o dar legitimidad al proceso de captura, procesamiento y transmisión de datos personales, que permitiera, por una parte, el flujo de información imprescindible para el funcionamiento de una sociedad moderna e informatizada; y, por otra, garantizara la no afectación de los derechos fundamentales de las personas" ${ }^{\prime 1}$.

En este sentido, la doctrina nacional ha propuesto, incluso, que la interpretación adecuada del derecho constitucional de protección de los datos personales consiste en la consagración del derecho a la autodeterminación informativa ${ }^{92}$. Esto es, el derecho a:

"Controlar la obtención, tenencia, tratamiento y transmisión de datos relativos a su persona, decidiendo en cuanto a los mismos las condiciones en que dichas operaciones puede llevarse a cabo" ${ }^{93}$.

Esta interpretación también ha sido confirmada por el Tribunal Constitucional, el cual resolvió que la norma constitucional citada:

"Resguarda lo que se denomina el derecho a la autodeterminación informativa. Es decir, se encarga de proteger a las personas de la circulación de la información que sobre ellas mismas existe en distintos centros de acopio. Dicho derecho es la dimensión activa del derecho a la vida privada [...]. El derecho a la autodeterminación, en cambio, implica controlar los datos que circulan sobre nosotros mismos" $"$.

Por lo tanto, la garantía constitucional sobre la protección de datos personales permite resguardar este tipo de datos, aun cuando se realiza un tratamiento de datos obtenidos de una fuente de acceso público o, bien, sean tratados en forma lícita por el responsable del tratamiento. Pues permite controlar el tráfico de datos personales en cualquier situación, sea un tratamiento que cumple o no con las formas y condiciones que establece la Ley n. ${ }^{\circ} 19628$.

En conclusión, mientras exista un dato personal en juego, el derecho del titular a proteger y controlar la circulación de la información que per-

${ }^{91}$ Álvarez-Valenzuela (2020), p. 2.

${ }^{92}$ Ibid.; Rausser (2018), p. 54.

${ }^{93}$ Op. cit., p. 53.

${ }^{94}$ Control de constitucionalidad del proyecto de ley que sanciona el acoso sexual de menores, la pornografía infantil y la posesión de material pornográfico (2011), p. 18. 
mite identificarlo, prevalece, incluso, por sobre los derechos de propiedad intelectual o un secreto empresarial ${ }^{95}$ del responsable del tratamiento. De hecho, es posible argumentar que en el derecho chileno no existe propiedad por sobre un dato personal, por dos razones:

i) Como dato, no es objeto de propiedad por el derecho civil y

ii) El contenido de ese dato es protegido por un derecho fundamental que escapa de las características del derecho real de dominio.

En el derecho extranjero, específicamente europeo, surgen conclusiones similares que señalan:

"El derecho fundamental a la protección de datos de carácter personal ni es un derecho de propiedad, ni puede serlo, ni necesita del instituto civil de la propiedad para justificar su tutela y las acciones que confiere a su titular y a otros interesados en el mismo"96.

En efecto:

"Nadie es propietario de si mismo, ni de su ni de sus atributos personales, y lo contrario supone una patrimonialización indebida de bienes no patrimoniales" $"$.

Sin embargo, lo cierto es que las decisiones anteriores no son solo jurídicas, sino políticas, porque dependen de cómo se interpreta en una sociedad determinada la naturaleza jurídica de un derecho fundamental (si es patrimonial o no). Por lo mismo, solo se plantea la discusión sobre la propiedad de los datos personales en el derecho comparado porque, al menos, desde el punto de vista de la autodeterminación informativa, se puede justificar que el derecho a proteger los datos personales, en el derecho chileno, debe prevalecer por sobre otros derechos en una economía basada en datos. No obstante, en este punto, tampoco es posible olvidar que el derecho a proteger los datos personales precisamente es

${ }^{95}$ En este punto es relevante señalar que el derecho de acceso consagrado al titular del dato le permite exigir al responsable "la información sobre los datos relativos a su persona, su procedencia y destinatario, el propósito del almacenamiento y la individualización de las personas u organismos a los cuales sus datos son transmitidos regularmente" (art. 12, inciso 1 de la Ley n. ${ }^{\circ} 19628$ de 1999). Es decir, el titular podrá conocer todo lo relativo al tratamiento de sus datos personales, pero el ejercicio de esta atribución no le da derecho a conocer la base de datos o conocimientos extraídos que constituyen un secreto empresarial. Por esto, pese a que efectivamente se "revela" parte del secreto con el ejercicio de un derecho de acceso, el titular del secreto -y responsable del tratamiento- tienen derecho a guardar reserva sobre el resto de la información que no se relacione con el dato personal del titular.

${ }^{96}$ Torre de Silva y López de Letona (2019), p. 849.

${ }^{97}$ Ibid. 
un derecho y según el Código Civil, existe una disposición que señala que sobre las cosas incorporales "tenemos una especie de propiedad" 98 .

Para finalizar este análisis, es necesario destacar que existe una alternativa que permite a los responsables del tratamiento actuar sin los límites de la Ley n. ${ }^{\circ} 19628$-o cualquiera que en el futuro la reemplace- esto es, el proceso de "anonimización" de datos. Un dato anonimizado es aquel:

"Que no puede asociarse a una persona identificada o identificable por haberse destruido el nexo con toda información que identifique al sujeto, o porque dicha asociación exige un esfuerzo no razonable, entendiendo por tal el empleo de una cantidad de tiempo, gastos y trabajo desproporcionados"99.

Por lo mismo, consiste en un dato que, si bien en su origen era un dato personal, ha dejado de serlo porque no permite identificar al titular, al destruir, en forma irreversible, su conexión con dicho sujeto.

Este proceso, al menos desde la perspectiva de la ciencia de datos, es clave porque permite trabajar lícitamente sobre datos que previamente fueron datos personales e, incluso, pueden generar resultados que sí pueden ser protegidos por derechos de propiedad intelectual o un secreto empresarial. Sin embargo, para poder aplicarlos otra vez habría que insistir que, al menos en la etapa inicial del proceso de anonimización, es decir, aquella donde sí existen datos personales, el tratamiento de dichos datos sea lícito y cumpla con las formas y condiciones establecidas en la ley.

\section{LA NUEVA ECONOMÍA BASADA EN DATOS EN EL CONTEXTO DE UNA CONVENCIÓN CONSTITUCIONAL}

En el marco de la discusión constitucional, una de las cuestiones más relevantes en relación con el derecho de propiedad es determinar si se mantendrá la misma postura sobre los bienes o cosas en los que puede recaer dicho derecho. En efecto, para la nueva economía basada en datos, esta decisión puede ser esencial, porque si se llegase admitir el ejercicio de un derecho de propiedad sobre otros bienes inmateriales que no son cosas incorporales, existirá un fundamento constitucional para justificar la existencia de un derecho de dominio sobre entes incorporales como los datos y, con ello, será necesario determinar además, si dicha propiedad, debe ser pública o privada.

\footnotetext{
${ }^{98}$ Art. 583 del Código Civil.

${ }^{99}$ PuYOL (2015), p. 213.
} 
Dicho de otra forma, la discusión sobre el alcance del derecho de propiedad tendrá importantes repercusiones en el libre acceso a la información y la exclusividad sobre los desarrollos obtenidos en técnicas y disciplinas que se dedican al estudio de los datos, porque existiendo un derecho de propiedad sobre este nuevo recurso, la protección jurídica no estará limitada según la naturaleza del contenido u otras creaciones relacionadas con el análisis de estos recursos. Por el contrario, se podrían establecer las bases para un nuevo marco normativo que permita restringir la libre circulación de la información, generar riqueza a quienes producen $\mathrm{u}$ ofrecen sus datos al mercado o, bien, limitar el uso y goce del recurso más valioso del siglo XXI.

Por esto, y sin intención de tomar ninguna postura al respecto, es necesario advertir la importancia de tomar una decisión consciente sobre los bienes susceptibles de ser protegidos por un derecho de propiedad, cuando, además, existen cada vez más nuevas categorías de cosas no clasificables bajo las normas del derecho civil. Asimismo, la atención de esta discusión también debiese enfocarse en el papel que representará la libre circulación de la información en el desarrollo de la futura sociedad chilena. Esto, pues, el acceso a la información, la transparencia, el uso de nuevas tecnologías y el desarrollo de nuevos modelos de negocios basados 138 en datos, se verán íntimamente afectados por los principios orientadores que se adopten en esta materia.

Por último, aunque no menos importante, la Convención Constitucional también invita a pensar sobre cómo se desea que se relacione el derecho de propiedad respecto a otros derechos fundamentales, como la protección a los datos personales. Ya que, aunque exista un cambio en los objetos susceptibles a ser protegidos por un derecho de propiedad, se debe tomar la importante decisión respecto de si el derecho de dominio prevalecerá o convivirá con los otros derechos constitucionales que forman parte de los atributos de la personalidad. Esto es, si es necesario proteger mediante el concepto de propiedad e integración del patrimonio, el ejercicio de los derechos fundamentales.

\section{Conclusiones}

En la sociedad actual, altamente digitalizada e interconectada, los datos se han transformado en el nuevo centro de la economía, ya que son un recurso esencial para el crecimiento económico, la creación de empleos y el desarrollo de nuevas tecnologías disruptivas. Por lo mismo, se han comparado con el oxígeno o el petróleo, porque son materias primas capaces de generar conocimiento de gran valor que permiten a distintas 
empresas o actores del mercado obtener ventajas competitivas, mejorar la eficiencia de sus procesos, etcétera.

Asimismo, han surgido distintas tecnologías y disciplinas que recopilan, almacenan y procesan datos para extraer conocimientos de valor, generando nuevos modelos de negocios basados en el estudio de este preciado recurso. Sin embargo, hasta la fecha, no existe una regulación especial que permita reconocer claramente a los dueños de estos nuevos bienes en la economía digital.

Atendido lo anterior, se propuso resolver si es posible configurar un derecho de propiedad sobre los nuevos activos de la economía basada en datos, especialmente sobre los datos entendidos como entidades distintas a su soporte y contenido. Para ello, se recurrió a las normas generales contenidas en la Constitución y el Código Civil, además de las leyes de Propiedad Intelectual e Industrial y la Ley de Protección de Datos Personales.

En virtud del marco normativo actual, se concluyó que los datos como entidades independientes de su contenido y dimensión física, no son susceptibles de ser protegidos por un derecho de dominio, porque no pueden ser clasificados como cosas corporales o incorporales según las normas del Código Civil. En consecuencia, no existe una relación de propiedad o especie de propiedad entre una persona y los datos, según las normas del derecho común. Del mismo modo, cuando se estudió desde el punto de vista constitucional, específicamente el art. $19 \mathrm{n} .^{\circ} 24$ de la Constitución, se sostuvo que no es posible argumentar que existe un derecho de propiedad sobre bienes inmateriales diversos a los ya regulados en el Código Civil, porque la doctrina interpreta esta disposición como una mera restricción a las cosas incorporales que, al mismo tiempo, son bienes susceptibles de apropiación.

No obstante, cuando se analizó el contenido de los datos, fue posible aplicar un régimen de propiedad con matices, específicamente a través de las normas de propiedad intelectual o industrial, porque nuestra legislación sí protege creaciones intelectuales expresadas en forma original o, bien, permite resguardar el contenido de un dato, cuando dicha información consista en secretos que ofrecen ventajas comparativas a su titular. Por esto, se recomienda distinguir el dato como entidad individual, de la información en él representada y el resto de las creaciones que se puedan desarrollar en este contexto, como las bases de datos o conocimientos extraídos de su análisis. De esta manera cumpliendo los requisitos de la legislación especial, estos activos pueden ser protegidos por otro tipo de "propiedad", como los derechos de autor y propiedad industrial.

Por consiguiente, es posible concluir que en el ordenamiento jurídico chileno es posible estructurar derechos de propiedad que permitan potenciar los nuevos modelos de negocios propios de la nueva economía basada 
en datos, pero no en base al dato en sí mismo, sino al contenido de este o las creaciones que se desarrollen a partir de su estudio. Además, cuando el objetivo sea determinar si existen herramientas jurídicas para proteger y excluir a terceros respecto del uso de cierta información, no solo será necesario evaluar si existe un derecho de propiedad sobre el contenido o las creaciones intelectuales relacionadas, sino, también, será indispensable definir el impacto de una regulación especial en dicho contenido, como la protección de datos personales.

\section{BibLIOGRAFÍA CITADA}

Alessandri, Arturo, Manuel Somarriva y Antonio Vodanic (2005). Tratado de Derechos Reales, Bienes. $6^{\text {a }}$ ed. Santiago: Editorial Jurídica de Chile. Tomo I.

Álvarez-Valenzuela, Daniel (2020). "La protección de datos personales en contextos de pandemia y la constitucionalización del derecho a la autodeterminación informativa”. Revista Chilena de Derecho y Tecnología, vol. 9, n. ${ }^{\circ} 1$. Disponible en https://rchdt.uchile.cl/index.php/RCHDT/article/view/57777 [fecha de consulta: 30 de mayo de 2021].

Comisión Europea (2017). "Comunicación de la Comisión al Parlamento Euro140 peo, al Consejo, al Comité Económico y Social Europeo y al Comité de las regiones 'La construcción de una economía de los datos europea'”. Disponible en https://eur-lex.europa.eu/content/news/building_EU_data_economy. html?locale=es [consultado el 30 de mayo de 2021].

Cruz-Coke Ossa, Carlos (2009). Instituciones políticas y derecho constitucional. Santiago: Ediciones Universidad Finis Terrae.

García Mirete, Carmen María (2014). Las bases de datos internacionales. Valencia: Tirant lo Blanch.

García Vidal, Ángel (2020). Big data e internet de las cosas. Valencia: Tirant lo Blanch.

GuZmán Brito, Alejandro (2019). Las cosas incorporales en la doctrina y en el derecho positivo. $2^{\mathrm{a}} \mathrm{ed}$. Santiago: Ediciones Jurídicas de Santiago.

López Sabater, Verónica (2017). Economía de los datos. Disponible en www.fundaciontelefonica.com/cultura-digital/publicaciones/624/ [fecha de consulta: 21 de mayo de 2021].

Moisés BARRIo, Andrés (2020). Manual de derecho digital. Valencia: Tirant lo Blanch. Peñallillo Arévalo, Daniel (2006). Los bienes. Santiago: Editorial Jurídica de Chile.

Puyol Moreno, Javier (2014). "Una aproximación a Big Data”. Revista de Derecho UNED, n. ${ }^{\circ}$ 14. Disponible en http://e-spacio.uned.es/fez/eserv/bibliuned: RDUNED-2014-14-7150/Documento.pdf [fecha de consulta: 31 de mayo de 2021]. 
Puyol Montero, Javier. (2015). Aproximación jurídica y económica del Big Data. Valencia: Tirant lo Blanch.

Rausser Monsálvez, Carlos (2018). Derecho al olvido. La protección de datos personales como límite a las libertades informativas. Santiago: DER Ediciones.

Real Academia Española (2014). Diccionario de la lengua española. 23a ed. Disponible en https://dle.rae.es/dato [fecha de consulta: 15 de mayo de 2021].

Romeu I Cónsul, Ramón (2019). "Las nuevas bases de datos. Big Data, desestructuración e Inteligencia Artificial”, en Susana Navas Navarro (dir.). Nuevos desafíos para el derecho de autor. Robótica, inteligencia artificial y tecnología. Madrid: Editorial Beus.

Sánchez García, Alejandro (2021). Derecho tecnológico: Principios, ideas y conceptos. Ciudad de México: Tirant lo Blanch.

Shоснат, Eden (2015). "Factor humano y resistencia", en Big Data. El poder de los Datos. Disponible en www.fundacionbankinter.org/documents/20183/42758/ Publicaci\%C3\%B3n+Big+data/cc4bd4e9-8c9b-4052-8814-ccbd48324147 [fecha de consulta: 31 de mayo de 2021].

Torre de Silva y López de Letona, Javier (2019). "Derecho civil de los datos". Anuario de derecho civil, vol. 72, n. ${ }^{\circ} 3$. Disponible en https://dialnet.unirioja. es/servlet/articulo?codigo $=7114232$ [fecha de consulta: 31 de mayo de 2021].

Walker EcheÑIQue, Elisa (2020). Manual de propiedad intelectual. $2^{\mathrm{a}}$ ed. Santiago: Thomson Reuters.

\section{Jurisprudencia citada}

Control de constitucionalidad del proyecto de ley que sanciona el acoso sexual de menores, la pornografía infantil y la posesión de material pornográfico (2011): Tribunal Constitucional, 12 de julio de 2011, rol n. ${ }^{\circ}$ 1894-2011.

\section{Normas citadas}

Constitución Política de la República.

Código Civil.

Ley n. ${ }^{\circ} 17336$ sobre Propiedad Intelectual. Diario Oficial de la República de Chile, Santiago, 2 de octubre de 1970.

Ley n. ${ }^{\circ} 19039$ sobre Propiedad Industrial. Diario Oficial de la República de Chile, Santiago, 25 de enero de 1991.

Ley n. ${ }^{\circ} 19628$ sobre Protección de Datos de Carácter Personal. Diario Oficial de la República de Chile, Santiago, 28 de agosto de 1999. 


\section{SIGLAS Y ABREVIATURAS}

ARCO Acceso, Rectificación, Cancelación y Oposición

art. artículo

dir. directora

ed. edición

etc. etcétera

GDPR Reglamento General de Protección de Datos Personales de la Unión Europea

https Hyper Text Transfer Protocol Secure

I.A. Inteligencia Artificial

Ibid. Ibidem (allí, en ese mismo lugar)

ISO International Organization for Standardization

Ley n. ${ }^{\circ} 17336$ Ley n. ${ }^{\circ} 17336$ sobre Propiedad Intelectual

Ley n. 19039 Ley n. ${ }^{\circ} 19039$ sobre la Propiedad Industrial

Ley n. ${ }^{\circ} 19628$ Leyn. ${ }^{\circ} 19628$ sobre Protección de Datos Personales

n. ${ }^{\circ}$ número

op. cit. opere citato (obra citada)

p. página

pp. páginas

UNED Universidad Nacional de Educación a Distancia

vol. volumen

www World Wide Web 